\title{
Educação Permanente em Saúde: experiências inovadoras em saúde mental na Atenção Básica à Saúde
}

\author{
Permanent Education in Health: innovative experiences in mental \\ health in Primary Health Care
}

Priscilla Regina Cordeiro', Rosilda Mendes', Flavia Liberman ${ }^{\mathbf{1}}$

DOI: $10.1590 / 0103-11042020 E 318$

RESUMO O processo de articulação da Rede de Atenção Psicossocial é um desafio diário vinculado à assistência integral à saúde e a estigmas sobre transtornos mentais, sendo necessário repensar estratégias que intensifiquem a articulação de maneira inclusiva, garantindo acesso a toda a população. Este artigo descreve uma pesquisa de intervenção de abordagem qualitativa, utilizando Oficinas como método de Educação Permanente em Saúde, apresentando os agentes comunitários de saúde como público-alvo. O objetivo deste estudo foi possibilitar a intervenção, a implementação e a análise dessa metodologia, com o intuito de promover um espaço de troca, criação coletiva e transformação da prática na produção diária de saúde entre profissionais e usuários com transtornos mentais, pensando sobre o fortalecimento do papel na Rede de Atenção Psicossocial segundo a Reforma Psiquiátrica. Esta pesquisa promoveu encontros com atividades reflexivas e aprendizagem inventiva que permitiram a 'construção conjunta', partindo de problemas identificados no cotidiano e construindo juntos a solução comum. Ao construir a solução, este estudo fortaleceu o relacionamento entre as equipes de atendimento da Rede de Atenção Psicossocial, incentivando esses profissionais a serem uma extensão do Centro de Atenção Psicossocial no território.

PALAVRAS-CHAVE Atenção Primária à Saúde. Saúde mental. Agentes Comunitários de Saúde. Educação profissional em saúde pública. Práticas interdisciplinares.

\begin{abstract}
The articulation process of the Psychosocial Care Network is a daily challenge linked to comprehensive health care and stigmas about mental disorders, and it is necessary to rethink strategies that intensify the articulation in an inclusive way, guaranteeing access for all the population. This article describes a qualitative approach intervention research, using workshops as a method of Permanent Education in Health, presenting the community health agents as a target audience. The purpose of this study is to enable the intervention, implementation and analysis of this methodology, aiming to promote a space of exchange, collective creation and transformation of the practice in the daily production of health among professionals and users with mental disorders, thinking the strengthening of the protagonism in the Psychosocial Care Network, according to the Psychiatric Reform. This research promoted meetings with reflective activities and inventive learning that allowed 'joint construction', starting with problems identified in daily life and building together the common solution. While building the solution, this study strengthened the relationship between the teams within those services of the Psychosocial Care Network, encouraging these professionals to be an extension of the Psychosocial Care Center in the territory.
\end{abstract}

1 Universidade Federal de São Paulo (Unifesp) - São Paulo (SP), Brasil.

cordeiro_to@hotmail.com
KEYWORDS Primary Health Care. Mental health. Community health workers. Education public health professional. Interdisciplinary placement. 


\section{Introdução}

A Reforma Psiquiátrica Brasileira, sancionada pela Lei Federal $n^{\circ} 10.216$, de 2 de abril de 2001, representou um avanço significativo para a integralidade da assistência em saúde e buscou potencializar os direitos e a proteção das pessoas em sofrimento psíquico, assegurando o acesso ao melhor cuidado e qualidade possível no Sistema Único de Saúde (SUS) ${ }^{1}$. Com vistas a esses avanços, a Reforma Psiquiátrica Brasileira preconiza a implantação de uma Rede de Atenção Psicossocial (Raps), de modo a articular ações entre os serviços que a compõem e expandir o cuidado para além dos espaços substitutivos extra-hospitalares ${ }^{2}$. Trata-se de uma estratégia que se caracteriza por práticas pautadas nos princípios da territorialização, da responsabilização e da ampliação das redes sociais existentes nas comunidades ${ }^{3}$.

A reabilitação psicossocial é compreendida como um conjunto de ações, centrado na pessoa, que consideram as expressividades do sofrimento, assim como a autonomia, o exercício da cidadania, os direitos humanos e a liberdade como fatores essenciais para a condução do cuidado pensado pela via da reinserção na sociedade. Tal conceito envolve, de maneira horizontal, todos os atores relacionados com esse cuidado, sejam eles usuários, familiares e profissionais de saúde, tratando-os como protagonistas da condução dessa reabilitação, tendo em vista ressignificar e aprimorar as habilidades e potências dos usuários em sofrimento psíquico inseridos em sua comunidade ${ }^{4}$. Nesse cenário, o Centro de Atenção Psicossocial (Caps) se revela como um serviço fundamental para a rede de atenção à saúde, uma vez que busca promover a desinstitucionalização ao integrar e auxiliar, também, na articulação entre os pontos da Raps, incluindo a Atenção Básica à Saúde (ABS). Nessa perspectiva, entende-se que aproximar as ações de saúde mental nos espaços da ABS, de acordo com as diretrizes da Política Nacional de Saúde Mental, é um dos propósitos que definem as ações que buscam “[...] a transformação de uma sociedade para conviver com a loucura"3(28). Contudo, a inclusão dessas ações ainda é um desafio, sendo fundamental a promoção de práticas que promovam uma rede de cuidados tecida no processo da Reforma Psiquiátrica, convidando os profissionais de saúde a sustentarem as diferenças ante os estigmas relacionados com o sofrimento psíquico.

Com vistas a oferecer ferramentas para a integralidade da atenção à saúde, o Ministério da Saúde instituiu uma importante estratégia política para o fortalecimento do SUS, denominada Educação Permanente em Saúde (EPS) ${ }^{5}$. A EPS dispõe sobre a modificação e transformação das práticas em saúde dos profissionais ao constituir uma ferramenta importante que busca desenvolver um trabalho em saúde inserido em um processo multiprofissional e interdisciplinar, coletivo, educativo dialógico e de incentivo ao protagonismo dos profissionais em relação ao desenvolvimento de sua formação6-8.

Tendo como cenário de investigação um dos territórios localizado no município de São Bernardo do Campo (SP), este artigo foi elaborado a partir da dissertação desenvolvida pela pesquisadora e terapeuta ocupacional pertencente a uma equipe de um Caps III. Busca-se aqui repensar o acompanhamento integral dos usuários em sofrimento psíquico no território e auxiliar nos processos de descentralização e de aproximação entre a ABS e o Caps, por meio de práticas criativas e inovadoras, tendo como parâmetro o processo de reabilitação psicossocial e a Reforma Psiquiátrica.

Nesse contexto, no que diz respeito à assistência em saúde mental na comunidade, observou-se que a articulação da ABS na Raps nesse território demonstra-se fragmentada, mostrando-se incipiente ou escassa em relação às ações intersetoriais, de cuidado e atenção em saúde mental, o que, indiretamente, pode favorecer o estigma, a institucionalização e o funcionamento manicomial. Entende-se que essa conjuntura, não exclusiva deste local - mas comum em outros territórios e espaços de saúde -, ecoa diretamente no 
acompanhamento do usuário em sofrimento psíquico, necessitando, portanto, de modificações. Assim sendo, as realidades precárias supracitadas acabaram por se constituir um problema de pesquisa.

Ao avaliar o território da pesquisa, assim como a dinâmica na qual a Raps se insere nesse local, é possível inferir que o maior engajamento dos Agentes Comunitários de Saúde (ACS) na atenção básica - estimulando-os quanto à corresponsabilização, por meio de ações coletivas - inseridos no processo de cuidado integral ao usuário em sofrimento psíquico poderia torná-los profissionais fundamentais em todo o processo de qualificação e articulação entre os serviços pertencentes à Raps, em especial, o Caps e a Unidade Básica de Saúde (UBS) em questão, favorecendo a percepção desses profissionais como protagonistas no cuidado integral, incluindo a saúde mental, equivalendo-se a uma extensão do Caps na comunidade, afinal, são eles os conhecedores desse território por atuarem e habitarem nele.

O presente artigo traz alguns resultados de uma investigação que tem também como intuito inspirar ações sobre as necessidades de transformação do cuidado em saúde mental, em consonância com os princípios do SUS ${ }^{9}$. Nessa direção, analisa a articulação do cuidado integralizado na Raps ao ressaltar a essencialidade e a importância da participação ativa e do protagonismo dos profissionais e usuários do SUS nos serviços que os agregam e contemplam, de modo a contribuir para a efetividade e a qualidade da assistência em saúde mental no território, de acordo com os princípios da reabilitação psicossocial e diretrizes da Reforma Psiquiátrica.

Dessa forma, o objetivo deste estudo é intervir, implementar e avaliar a EPS, como estratégia norteadora, ao descrever e analisar o processo de elaboração de Oficinas como ferramentas de recurso para a articulação entre o Caps e a UBS pertencentes à Raps. Para a construção desse percurso, propuseram-se ações e atividades que busquem intervir no ato do encontro, bem como trocas de experiências que se cruzam entre vivências, interesses e perspectivas e que promovam aprendizagem e criação de ações coletivas entre os ACS e usuários em sofrimento psíquico convidados.

\section{Material e métodos}

O percurso metodológico desta pesquisa baseou-se no referencial de uma pesquisa-intervenção de abordagem qualitativa. As características de uma pesquisa-intervenção potencializam essa prática investigativa, pois suas ações ocorrem no contexto pesquisado perante os problemas e as demandas que carecem de soluções; possibilita, ainda que a pesquisa seja participativa, de modo que tanto o pesquisador quanto os participantes da pesquisa se apresentem como sujeitos ativos de um estudo em movimento ${ }^{10}$.

O público-alvo da pesquisa foram as 12 ACS, que integravam duas equipes de uma UBS localizada no município de São Bernardo do Campo (SP). A opção por desenvolver a pesquisa com essas ACS deveu-se ao anseio de privilegiar a voz desses atores sociais, enfatizando suas percepções e os propósitos de suas atuações, considerando-as como possíveis protagonistas no processo de territorialização na equipe do Caps.

Este estudo contou ainda com a participação de cinco usuários em sofrimento psíquico, inseridos no mesmo Caps III. A participação desses sujeitos não deve ser confundida com o público-alvo, mas, sim, entendida como a presença de personagens que trazem discussões importantes relacionadas com o sofrimento psíquico, ao compreender que estes possuem domínio sobre os temas refletidos, considerando as próprias vivências no decorrer de suas vidas. Isto é, a participação dos usuários em sofrimento psíquico nas Oficinas poderia possibilitar, também, o confronto com as questões relativas aos estigmas, ao desconhecimento e ao preconceito, ao serem conduzidas pelas declarações apropriadas e pontuais daqueles sujeitos. 
Onze Oficinas foram realizadas semanalmente no território de abrangência da UBS e em serviços de saúde inseridos na Raps, com a duração de uma hora cada, contemplando as atividades, o tempo para a reflexão coletiva e o encerramento do encontro do dia. As propostas iniciais das Oficinas pretendiam oportunizar espaços de criação em grupo, trocas de experiências, de escuta, aprendizagem e de transformação da prática no cotidiano de produção em saúde, considerando os pressupostos da EPS.

O quadro 1 a seguir apresenta parte da organização estrutural e da análise das atividades ofertadas nas Oficinas:

Quadro 1. Organização estrutural e temas propostos para Oficinas

\section{Oficina 1 - Conhecendo a Rotina das ACS}

Apresentação das propostas e vivências nas Oficinas.

Primeira vivência com as ACS, propondo conhecer sua rotina e processos de trabalho.

\section{Oficina 2 - Aquecimento}

Apresentar os objetivos de cada encontro para a equipe, pactuação de contratos e horários e conhecer as expectativas do grupo

Oficina 3 - Conhecendo a Rede Viva

Levantamento das expectativas dos participantes na pesquisa. Dificuldades e Potências desta Raps compreendidas pelas equipes.

Oficina 4 - Quebrando paradigmas

Troca de experiências com a equipe da UBS e usuários do Caps III, por meio das histórias e vivências da vida no Manicômio e reflexões referentes à articulação das Redes de Saúde e ao fechamento de Hospitais Psiquiátricos.

\section{Oficina 5 - Conhecendo a Raps - Assimilando as experiências}

Visita aos serviços da Raps existentes no território com as ACS. Atividade de vivência no Caps III.

\section{Oficina 6 - Prática, Ação e Equipe}

Atividade direcionada ao trabalho em Equipe e importância da construção/articulação da Raps

\section{Oficina 7 - Cartografia de Forças}

Estudo de Caso: elaboração criativa do caminho de usuários no território e do trabalho em Rede, utilizando como dispositivo o Ecomapa.Propostas possíveis para o Projeto Raps e UBS.

\section{Oficina 8 - Articulação das Redes de Saúde - Problemas e Criações}

Identificação de problemas ante a articulação das Redes de Saúde e jogo de ideias de como potencializá-la (Brainstorm de Criações).

\section{Oficina 9 - O Território como Cenário de Cuidado}

Criar coletivamente estratégias e soluções para os problemas apresentados referentes ao tema e potenciais de um profissional multiplicador.Ponto de partida para Projeto a Raps e UBS.

\section{Oficina 10 - Repensando a prática}

Finalização do Projeto Coletivo com a elaboração das propostas possíveis para a Raps e o território.

\section{Oficina 11 - $\mathrm{O}$ que faremos com o que aprendemos?}

Discussão final sobre o protagonismo e a iniciativa na articulação da Raps na Atenção Básica à Saúde e todo o processo vivido durante as Oficinas.

\section{Roda de conversa - Expressão e Parceria}

Roda de Conversa com tema livre entre os participantes, profissionais convidados e Gestão, tendo entre os objetivos do encontro observar e avaliar as mudanças efetivas, o Hábito na rotina de trabalho e devolutiva da equipe

Fonte: Elaboração própria. 
Essas Oficinas baseiam-se em metodologias que possibilitam a participação ativa de todos os integrantes do grupo e se revelam como ferramentas potencializadoras para a transformação das práticas cotidianas, permitindo o pesquisar com os sujeitos em análise, a aprendizagem significativa e a construção coletiva a partir dos problemas identificados" ${ }^{11}$ Destaca-se que a EPS, compreendida como um processo pedagógico, parte do pressuposto da aprendizagem significativa, uma vez que pretende proporcionar a reflexão pelos profissionais de saúde sobre a sua formação e o seu cotidiano do trabalho ao adotar a problematização do processo de trabalho, tendo em vista a transformação das práticas de saúde ${ }^{\mathbf{8}}$.

A pesquisa foi aprovada pelo Comitê de Ética em Pesquisa da Universidade Federal de São Paulo Hospital São Paulo (Unifesp-HSP) (CAAE:4683.4415.3.0000.5505).

\section{Levantamento e análise de dados}

Os dados foram produzidos por meio do registro em Diários de Bordo das 11 Oficinas e de uma Roda de Conversa realizada após quatro meses do término da última Oficina. Tais registros objetivaram preservar o caráter de expressão subjetiva, singular e coletiva das vivências. O Diário de Bordo tornou-se uma importante forma de registro escrito, oportunizando a descrição livre das expressões e impressões, durante cada encontro, a partir do objetivo e do subjetivo da experiência vivida no processo de criação ${ }^{12}$.

A etapa da análise do conteúdo dos Diários considerou a organização metodológica desta investigação, destinando-se à interpretação dos instrumentos utilizados na coleta de dados, para uma descrição sistemática, singular e coletiva do conteúdo. Os dados foram submetidos à análise de conteúdo na perspectiva de $\operatorname{Bardin}^{13}$, complementada pela abordagem de Minayo $^{\mathbf{1 4}}$, mediante leitura exaustiva daquilo que foi colhido, tendo sido organizados em quatro categorias: Práticas coletivas de pesquisa; Educação Permanente em Saúde: Oficinas como espaços de valorização, saberes e relações; Reformas em movimento: as práticas de território como garantia ao cuidado da loucura e Desafios e Estratégias para a Articulação da Rede de Atenção Psicossocial.

\section{Resultados e discussões}

\section{Práticas coletivas de pesquisa}

Na elaboração da pesquisa e no decorrer das Oficinas, buscou-se criar espaços que procurassem favorecer o diálogo, valorizando as diferentes vozes entre o grupo, tornando significativo o que cada participante representava de relevante e de novidade para complementar aquilo que já se compreendia e se defendia ${ }^{15}$. Logo, é coerente apontar que o que norteou o foco analítico e a discussão dos resultados, colhidos por meio dos instrumentos de coleta de dados, foi a possibilidade de colocar em análise o valor do protagonismo, da participação 'com', e não 'sobre' os participantes da pesquisa; e, consequentemente, das ações que propunham intensificar as relações e a articulação com os serviços da Raps.

Durante as Oficinas, foi possível, com as ACS e os usuários convidados, realizar visitas aos serviços da Raps, entre eles, os Caps existentes no território, a equipe de Consultório de Rua, a associação de usuários e familiares e o Pronto Atendimento de Psiquiatria. Esses momentos pretendiam garantir o conhecimento do fluxo e das relações entre as equipes e os usuários no território pelas ACS que participavam da pesquisa.

Na Roda de Conversa com as ACS, os usuários, os profissionais pertencentes às equipes (Caps e UBS) e a gestão da UBS para a discussão sobre os impactos das Oficinas, foi possível refletir sobre a participação nas Oficinas e os impactos no cotidiano do trabalho e sobre as transformações de olhares e falas referentes 
ao cuidado em saúde mental. Observou-se que a ambição de tornar os serviços da Raps parceiros não estava sendo endossada somente pelos desejos da pesquisadora, mas também pelas respostas potencializadas nas falas de cada ACS.

Depois que a gente ganhou essas Oficinas, a gente teve outra visão do Caps [...]. Então, eu acho que foi um recomeçar pra gente. Foi uma coisa boa! Assim, a gente tem mais visão do que é o Caps e de como trabalhar na rua com as pessoas que precisam do Caps. (ACS 1).

Aquilo que, inicialmente, havia sido compreendido como problema, aos poucos, foi se transformando em estratégias de ações. Na Roda de Conversa, notou-se que as propostas traçadas nas Oficinas já faziam parte da rotina, sendo possível perceber que esse formato de encontro é também um espaço de aprendizado na EPS, ao possibilitar a troca entre os diferentes atores sobre a realidade dos serviços de saúde nos quais estão inseridos e os impactos e propostas resultantes dos encontros e ações vivenciadas nas Oficinas ${ }^{16}$.

Nas Oficinas, ao realizar atividades disparadoras de reflexões sobre as práticas em saúde, buscou-se estimular os participantes a serem multiplicadores e protagonistas de ações descentralizadoras na articulação dos serviços da Raps, como mencionou a ACS:

Eu acho, assim, que a gente tem que ser multiplicador, né? Tudo o que a gente aprendeu nesse tempo que ficamos juntos, temos que ir distribuindo, né? Na comunidade, né? Nas famílias! Porque foram temas muito interessantes, e a gente precisa ser multiplicador de tudo isso pra dar continuidade. (ACS 1).

Buscou-se também sensibilizá-los a se tornarem parceiros ativos na defesa dos direitos em saúde mental, cidadania e do cuidado integral dos usuários em sofrimento psíquico. Essas ações incitam uma transformação social da ABS, caracterizando-se como novas formas coletivas de lidar com "[...] questões do sofrimento psíquico, buscando a criação e consolidação das redes existentes no território"3(42), como, inclusive, descreve a ACS no relato a seguir:

União, eu acho assim.... Pra um trabalho ser bem feito, pra toda a rede funcionar, acho que tem de ter a união por todos os profissionais. Acho que a união precisa acontecer pro trabalho funcionar [...] pra que a rede funcione e flua melhor. (ACS 2).

No decorrer de cada Oficina, era possível observar como as conexões criadas a cada encontro simbolizam as conexões que podem ser articuladas na rede e na comunidade.

Então, a gente vai se cuidando de acordo com cuidado que vão nos oferecendo; através do ol har, do amor, porque não é só o profissional, é também a presença do amor incondicional, que é aquilo que a gente espera e que acontece. É isso. Sejam bem vindos ao Caps vocês também. Aqui é uma nova vida! (C. usuária convidada).

\section{Educação Permanente em Saúde: Oficinas como espaços de valorização, saberes e relações}

Tendo a EPS como norte desta pesquisa, as atividades propostas em cada Oficina almejavam valorizar os diferentes saberes e reflexões sobre as estratégias de intervenção e transformação da prática de produção em saúde. Buscou-se pensar em estratégias que intensificassem o processo de articulação com os serviços da Raps e, consequentemente, garantissem o acesso de qualidade a atenção integral à saúde do usuário em sofrimento psíquico.

Tais estratégias demandavam ações que precisaram ser analisadas, sobretudo no que tange à sua aplicabilidade e ao imprevisível, pois envolviam desafios e barreiras, não somente institucionais, mas também 
relacionados com as concepções de cuidado em saúde mental de cada profissional de saúde, particularmente, naquele contexto. Os resultados esperados dependiam não só de mudanças do processo de trabalho, mas também de mudanças paradigmáticas que se relacionassem com as transformações individuais sobre o olhar dirigido a si e ao outro.

Nessa perspectiva, os resultados da EPS aparecem quando, de fato, os profissionais de saúde mostram-se sensibilizados, no sentido de que, no "no ambiente do trabalho, se deve valorizar as trocas de conhecimentos e experiências e, assim, ir redescobrindo novos caminhos para as intervenções e o cuidado em saúde"16(1476) e, consequentemente, tornando o percurso de aprendizagem de cada profissional participante permanente ao modificar a sua atuação profissional e qualificar o cuidado no serviço de saúde e no território.

Logo, o propósito das Oficinas não foi somente ensinar coisas novas relacionadas com o cuidado em saúde mental, mas propor ao grupo experiências e aprendizados a partir de novidades promovidas em uma relação horizontal, levando-se em conta a possibilidade de problematizar com o coletivo, aprendendo outros modos de fazer, ofertar e compreender a atenção em saúde direcionada ao usuário em sofrimento psíquico ${ }^{17}$. O foco, desse modo, era possibilitar aprendizagens recorrendo à produção de novos conhecimentos, às vivências positivas e aos afetos atrelados às dimensões subjetivas que envolvem e movimentam

[...] o pensamento, a imaginação, a criatividade, a potência (para estabelecer conexões com pessoas e equipamentos), a sensibilidade, a sociabilidade e a afetividade ${ }^{\mathbf{8 ( 5 )}}$.

Vivenciar as Oficinas, contando com a participação dos usuários em sofrimento psíquico frequentadores do Caps, das ACS e da pesquisadora - todos em um mesmo patamar de valorização de saberes -, possibilitou repensar, em grupo, os lugares enfraquecidos que ainda segregam e institucionalizam o cuidado e que precisam ser reavaliados e revalidados na articulação da Raps. Conforme a fala de um dos usuários participantes:

O Caps vem se desenvolvendo na maneira do paciente. O Caps, não só eu, mas a maioria que está lá, viu ele se desenvolvendo. Já estou de 4 a 5 anos por lá [...] e eu acho que, se vocês quiserem um dia fazer uma visita ao Caps III, será de grande valia para nós e, principalmente, para vocês. (J. usuário convidado).

A fala da ACS que vivenciou as Oficinas ressalta a importância do convite do usuário sobre o (re)conhecimento do Caps por profissionais de outros serviços de saúde, para o fortalecimento da Reforma Psiquiátrica, ao mencionar: "Hoje, eu vejo que o Caps éuma rede de apoio para a pessoa, inclusive, voltar para a sociedade e não viver trancada. É só mais um apoio, um suporte" (ACS 3).

Pode-se dizer que as ACS e os usuários participantes, entendidos aqui como protagonistas do SUS, assim como a pesquisadora, puderam "compartilhar, ensinar e aprender" juntos, construindo e desconstruindo "[...] concepções, ideias e conceitos acerca da saúde, de sua produção e operação e de seus papéis"19(6). A promoção de espaços de relações horizontais para repensar os processos da Reforma Psiquiátrica, pesquisando com os usuários em sofrimento psíquico, possibilitou momentos empáticos e de trocas reais de experiências, devido à disponibilidade e ao exercício do empoderamento de cada sujeito ao transmitir, para o grupo, suas vivências de sofrimentos e de progressos relacionados com os acontecimentos de suas vidas atreladas ao sofrimento psíquico. Foi o que demonstrou a ACS em sua fala:

Eu imaginava: Nossa, esses loucos tudo na rua! Todos esses loucos na rua, vai ficar feia a situação! Mas aí descobri que não tem nada a ver. Simplesmente, não tiraram do hospital e jogaram na rua. Existe uma reabilitação pra saírem. Esse trabalho é muito importante. (ACS 4). 


\section{Reformas em movimento: as práticas de território como garantia ao cuidado da loucura}

No decorrer das Oficinas, os usuários convidados contaram que a realidade institucional, pautada na lógica manicomial, ainda persiste e que, há até pouco tempo, viver entre os muros do manicômio era a única opção para muitos doentes mentais. Segundo eles, o confinamento asilar era o destino comum e certo às pessoas em sofrimento psíquico, conforme mencionado por uma das convidadas:

Então, você ficava condenado, sem ter praticado um crime, entendeu? E, quanto mais você pede uma melhora no seu tratamento, pior eles tratavam você. Você não pode reivindicar, você não pode pedir, não pode fazer nada. (C. usuária convidada).

Outro participante compartilha suas mais de 45 internações nos diversos hospitais psiquiátricos, durante longos anos:

Eu não sei muito bem, mas acho que [foram] umas 45 [internações] em hospital psiquiátrico. Mais ou menos isso! Tem tanta coisa que passei, mas, se não fosse pela minha força, minha braveza e eu deixasse correr do jeito que estava acontecendo lá no hospital, eu não estaria vivo, não estaria mais aqui. Estaria morto. (M. usuário convidado).

Durante as Oficinas e por meio dos relatos, gentilmente compartilhados pelos usuários convidados - narrativas sobre suas histórias de vida e sobre o tratamento desumano que lhes foi ofertado após diagnósticos que os rotularam e os obrigaram a uma forma de vida trancafiada em espaços passíveis de violência, traumas e cronificação -, foi possível evidenciar como é importante repensar o modelo substitutivo extra-hospitalar, no percurso percorrido pela Reforma Psiquiátrica Brasileira.

Buscou-se, também, refletir, dentro dessa realidade que os usuários compartilharam com o grupo, a importância dessa ruptura, haja vista as cicatrizes que as instituições psiquiátricas deixaram em suas vidas e nas de muitas outras pessoas.

Perto de uns 27 anos vivendo este tipo de tratamento, assim, condicionado a perdas [...], você fica atrofiado. Até você recuperar o hoje, aqui fora, é muito difícil. Não é fácil, não. [...] Eu fui pra casa, [...] eu não queria sair de casa, porque eu tinha rejeição do mundo, da vida, de tudo. (C. usuária convidada).

Doía muito, hein?! Não era fácil, não. E, com a vinda e a mudança do sistema de tratamento de saúde mental, revolucionou e mudou completamente, porque o usuário do sistema de saúde tem a liberdade. Ele é livre! [...] A pessoa sente que ela é livre. (J. usuário convidado).

A aproximação dos serviços de saúde mental dos demais profissionais de saúde é o caminho que talvez possa garantir o avanço e a manutenção do processo de desinstitucionalização. Para descentralizar o cuidado e não transformar os serviços substantivos em novas instituições que segregam e isolam, mesmo que de 'portas abertas', é preciso unifica-los e integrá-los à Raps, em especial à ABS, por meio de estratégias que instaurem novos paradigmas de cuidado e atenção para o usuário em sofrimento psíquico, bem como o fortalecimento das ações e discussões relacionadas com a desmitificação da loucura nas dimensões social, ética, política e cultural, interligadas à Reforma Psiquiátrica ${ }^{3,20}$.

Os usuários, protagonistas de suas histórias, compartilharam, com as ACS, as razões para a sustentação de uma rede de cuidados, pautadas na Reforma Psiquiátrica. Razões estas óbvias para quem conhece 'na pele' a realidade da assistência manicomial, sobretudo quando comparada com a atual atenção no cuidado em saúde mental e com o investimento em propostas terapêuticas singulares no território. Aqueles sujeitos mostraram que, para além de estarem ali como convidados, compor as Oficinas com a pesquisadora era criar, também, espaços que oportunizassem a conquista de 
novos parceiros para a Reforma Psiquiátrica, conforme a fala da usuária convidada durante uma das Oficinas:

A autonomia e o empoderamento, tudo isso que tem acontecido e era coisa que a gente, em outros momentos, almejava. Então, a gente ficava confinado. A gente estava tendo perdas, e elas eram irreparáveis. Ninguém sentia que nós estávamos perdendo e nós continuávamos perdendo. $E$, agora, com este novo investimento, eu acho que não haverá mais, futuramente, tantas pessoas que terão tantas perdas. Elas terão ganhos! (C. usuária convidada).

\section{Desafios e Estratégias para a Articulação da Rede de Atenção Psicossocial}

Ao iniciar a construção do projeto inicial da pesquisa aqui relatada, não era possível imaginar para quais caminhos ele se dirigiria. Os objetivos iniciais se relacionavam com a mera identificação das dificuldades encontradas pelos profissionais da ABS em relação à articulação com os demais serviços da Raps e como auxiliá-los no aprimoramento do cuidado. Pensando em como materializar essas ações, surgiram as Oficinas como ferramentas que poderiam pôr em prática essas discussões, de forma a torná-las mais vivas e mais interessantes.

No entanto, para que essas vivências acontecessem e provocassem transformações reais, os objetivos não poderiam ser direcionados somente para a dinâmica de cuidado e processos de trabalho da UBS, mas também para as práticas intrínsecas de cada profissional. Logo, o desejo era de que a participação nessas Oficinas provocasse mudanças internas relacionadas com o cuidado em saúde mental e no cuidado integral ofertadas pela ACS participante, em um processo que fizesse sentido a todos os envolvidos, desde a gestão, que deveria priorizar esses espaços de formação, até cada profissional, visto que não deveria ser obrigatório.
A participação nesta pesquisa sugere a inserção das ACS e dos usuários convidados em um processo coletivo e vivo, contornado pela subjetividade de cada participante que compõe o grupo, considerando, pois, suas experiências, percepções e formas de vida. $\mathrm{O}$ convite direcionado às ACS foi uma aposta da pesquisadora, como terapeuta ocupacional pertencente à equipe do Caps, após vivenciar com esses profissionais o compartilhamento do cuidado integral no território, observando as possíveis potências dessa parceria no cotidiano de trabalho.

O convite direcionado aos usuários em sofrimento psíquico tratava-se, inicialmente, de uma ideia utópica da pesquisadora, ao pensar que, abrindo espaços nas Oficinas para escutá-los, poderia desencadear uma transformação do cuidado voltado a eles naquele território. Contudo, a participação ativa desses usuários nas Oficinas foi marco de trocas essenciais para a abertura e a proximidade de todos os participantes, fortalecendo e provocando inquietações, em especial, na pesquisadora, que passou a observar que essa interação incentivava o diálogo, as relações e validações de forma horizontal, favorecendo um caminho para a aprendizagem inventiva ${ }^{\mathbf{2 1}}$ e reflexões de conceitos para cada participante.

Realizar uma pesquisa tendo a EPS como estratégia norteadora de suas técnicas - nesse caso, as Oficinas - possibilitou que a construção fosse coletiva do início ao fim do estudo. Motivar o grupo a procurar soluções para os problemas identificados em um coletivo tornou esse processo provocativo e inspirador. A construção coletiva favoreceu o discurso protagonista, de participação social e de superação de estigmas, em um processo de criação de afetos, em que foram possíveis trocas reais, de saberes e experiências, o que era fundamental para a proposta deste estudo.

Compreende-se, então, que a pesquisa, tendo seu desenvolvimento preparado com os participantes, provocou a construção de um processo de potências de relações entre os diversos atores, o qual pode se manter vivo, 
inclusive, após o término do estudo, considerando, assim, que a estratégia da EPS torna os processos formativos um processo de invenção coletiva, de construção em conjunto, que valoriza as relações e o papel de cada participante.

Representada no estudo, sugerir que as discussões não se embasassem somente em concepções teóricas e observações do campo, mas, também, na proposta de encarar os participantes desta pesquisa como atores ativos foi uma surpreendente maneira de entender o que é ser protagonista, pois, dessa maneira, foi possível compreender aqueles indivíduos como sujeitos pensantes, produtores de suas experiências. As possibilidades de pesquisar 'com' os protagonistas, e não ‘sobre' eles, pode conduzir as práticas investigativas a resultados reais e afetivos, além de desenvolver ações propostas que interviriam no campo de pesquisa.

As relações de sofrimentos e de conquistas, compartilhadas em todos os momentos da pesquisa, permitiram que os participantes, tanto ACS quanto usuários convidados, pensassem, coletivamente, em soluções criativas. A proximidade dessas relações com as vivências nas Oficinas, intencionando à produção de afetos como forma de qualificar e aprimorar o agente de saúde em relação ao cuidado integral em saúde, definiu caminhos para alcançar a qualificação dos cuidados, das parcerias entre os serviços da Raps e o protagonismo das ACS.

Nessa perspectiva, levando-se em conta a metodologia da EPS, os objetivos desta pesquisa e os problemas iniciais identificados, este estudo se insere em um processo formativo que, guiado por encontros afetivos ${ }^{22}$, necessitava do desejo, da abertura e da disponibilidade de cada participante para que, em seguida, ele se permita transformar por meio da aprendizagem, da interação e do vínculo com o outro, fazendo desse processo, que lhe afeta e faz sentido, o próprio processo norteador de trabalho. Para obter resultados em uma invenção coletiva que valoriza conhecimentos e saberes, é necessário propor ações que façam sentido em uma metodologia significativa, possibilitando que estas se moldem e se reestruturem de acordo com a realidade do contexto em que se inserem.

O entusiasmo em compartilhar uma Raps efetiva se mostrou presente a cada encontro, $\mathrm{e}$ na aproximação das participantes, nesse contexto, fortalecida por meio do estabelecimento de vínculos e da aproximação com os usuários. Da mesma forma, as participantes sugeriram, durante os encontros, que as Oficinas fossem ofertadas a outros ACS, a outras UBS e a outros territórios, evidenciando, pois, a compreensão da importância de compartilhar esse cuidado e de intensificar a articulação com os serviços que compõem qualquer Raps. A cada encontro, foi possível observar o crescimento do desejo das profissionais pesquisadas de se aproximarem das discussões como parceiras do cuidado integralizado e, mais ainda, como parceiras do Movimento da Luta Antimanicomial.

As Oficinas se revelaram como espaços de escuta, de acolhimento e de voz para as potências e reflexões quanto ao lugar social da loucura na sociedade, assim como para as práticas das ACS, demonstrando o quanto é preciso ter encontros que possibilitem a reinvenção da clínica como "[...] espaço de efetivo engajamento e responsabilização para com o sofrimento humano, de construção de possibilidades de vida e de produção de subjetividades"23(599), por meio de intervenções criativas e afetivas, "sem deixar de acolher, ouvir, respeitar e cuidar do indivíduo"24(4), para que o cuidado compartilhado em saúde mental realmente aconteça.

\section{Considerações finais}

Reconhecer a ABS como componente fundamental para a Raps é promover a melhoria do acesso e da qualidade do cuidado integral em saúde, tratando-o como responsabilidade de todo o território, ampliando e articulando os "pontos de atenção à saúde" para aos usuários em sofrimento psíquico e respeitando aos "[...] direitos humanos, garantindo a autonomia e a liberdade das pessoas"25 no âmbito do SUS. 
Este estudo demonstrou que vivenciar processos norteados pela EPS, no contexto da ABS - e, da mesma forma, uma importante estratégia para compor os desafios que a Reforma Psiquiátrica -, apesar de desafiadores, viabilizou discussões permeadas por atividades com conteúdos tecnológicos e referenciais necessários, porém, exigindo também a implementação de espaços que promovam reflexões e discussões sobre a prática diária de trabalho, com os atores ativos (usuários, profissionais de saúde, gestor, entre outros) que façam parte desse coletivo, de modo a produzir mudanças institucionais e territoriais verdadeiras e contínuas ${ }^{26}$.

Logo, pode-se afirmar que a EPS, utilizada como norte da construção das Oficinas, favoreceu a elaboração do processo de criação coletiva e aprendizagem significativa, demonstrando que, quando as relações afetivas são permitidas entre o grupo, torna-se possível aprender ao mesmo tempo que se ensina. Assim sendo, pode-se considerar essa metodologia é uma importante estratégia para compor os desafios que a Reforma Psiquiátrica apresenta na construção da Raps.

Com base na perspectiva de Paiva e Yamamoto ${ }^{27(568)}$, é possível concluir que a cultura manicomial enraizada em "[...] mentes e instituições durante anos não são solúveis facilmente". Propor espaços em que a voz dos usuários em sofrimento psíquico possa ser escutada horizontalmente pode se mostrar como um recurso potente na "humanização do cuidado na rede territorial"27(568) que favoreça um modelo de sistema de saúde "inclusivo, interdisciplinar e humanizado"3(22) e de formação de lideranças na comunidade de modo que estas atuem na garantia de direitos do usuário em sofrimento psíquico e de sua circulação em espaços abertos.

Compreendeu-se que os espaços de encontro proporcionados pelas Oficinas possibilitaram o entendimento de que, mais do que a intensificação da articulação com os serviços da Raps, é preciso ter em mente a importância de conquistar novos seguidores para a Luta Antimanicomial. Afinal, "a Reforma Psiquiátrica é um processo de constante reflexão e construção de saberes sobre a loucura e seu lugar social"27(568), que, quando estimuladas, promovem resultados consideráveis.

É possível entender, diante do aludido, que não são, necessariamente, as Oficinas aqui propostas que irão mudar a forma como cada ACS pensa o cuidado em saúde mental, mas, sim, as relações afetivas, as trocas de experiências, as vivências, o conhecimento dos serviços da Raps e, até mesmo, as histórias de vida de cada usuário. Isso porque as ações que compõem esse processo fizeram parte de uma invenção coletiva, que, de forma ativa, buscou incitar a ACS, tornando-a profissional protagonista, ao desempenhar um papel importante no incentivo a liberdade de acesso ao cuidado integral em saúde e na desconstrução das práticas de institucionalização da loucura, promovendo uma rede de solidariedade, respeito e cumplicidade no território.

\section{Colaboradoras}

Cordeiro PR (0000-0001-7029-5412)* contribuiu para elaboração e delineamento do estudo, produção, análise e interpretação dos dados, redação e revisão do manuscrito. Mendes R (0000-0001-5680-1657)* contribuiu para análise dos dados e revisão do manuscrito. Liberman F (0000-0001-8563-5993)* contribuiu para elaboração e delineamento do estudo, análise dos dados e revisão do manuscrito. 


\section{Referências}

1. Brasil. Ministério da Saúde. Decreto-Lei no ${ }^{\circ} 10.216$, de 6 de abril de 2001. Dispõe sobre a proteção e os direitos das pessoas portadoras de transtornos mentais e redireciona o modelo assistencial em saúde mental. Diário Oficial da União. 9 Abr 2001. [acesso em 2019 set 27]. Disponível em: http://www2.camara. leg.br/legin/fed/lei/2001/lei-10216-6-abril-2001-364458-publicacaooriginal-1-pl.html.

2. Amarante P. Saúde Mental e Atenção Psicossocial. Rio de Janeiro: Fiocruz; 2007.

3. Souza AC. Estratégias de Inclusão da Saúde Mental na Atenção Básica: um movimento das marés. São Paulo: Hucitec; 2015.

4. Lussi IAA, Pereira MAO, Junior AP. A proposta de reabilitação psicossocial de Sarraceno: um modelo de auto-organização? Rev. Latino-Am. Enfermagem, [internet], 2006 [acesso em 2019 set 28]; 14(3):448456. Disponível em: http://dx.doi.org/10.1590/S010411692006000300021.

5. Brasil. Ministério da Saúde, Secretaria de Gestão do Trabalho e da Educação na Saúde, Departamento de Gestão da Educação em Saúde. Política Nacional de Educação Permanente em Saúde. [internet]. Brasília, DF: Ministério da Saúde; 2009 [acesso em 2019 set 28]. Disponível em: http://bvsms.saude.gov.br/bvs/ publicacoes/politica_nacional_educacao_permanente_saude.pdf.

6. Ceccim RB, Feuerwerker LCM. O quadrilátero da formação para a área da saúde: ensino, gestão, atenção e controle social. Physis. 2004; 14(1):41-65.

7. Figueiredo EBL, Silva APA, Abrahão AL, et al. Efeito pororoca na educação permanente em saúde: sobre a interação pesquisa-trabalho. [internet] Rev. Bras. Enfermagem, 2018 [acesso em 2019 out 2019]; 71(sup14):1768-1773. Disponível em: http://dx.doi. org/10.1590/0034-7167-2017-0462.

8. Ferreira L, Barbosa JSA, Esposti CDD, et al Educação Permanente em Saúde na atenção primária: uma revisão integrativa da literatura. [internet] Saúde debate. 2019 [acesso em 2020 jun 30]; 43(120):223239. Disponível em: https://www.scielo.br/pdf/sdeb/ v43n120/0103-1104-sdeb-43-120-0223.pdf.

9. Brasil. Ministério da Saúde. Decreto-Lei no 8080 , de 19 de setembro de 1990. Dispõe sobre as condições para a promoção, proteção e recuperação da saúde, a organização e o funcionamento dos serviços correspondentes e dá outras providências. Diário Oficial da União. 20 Set 1990 [acesso em 2019 set 28]. Disponível em: http://www.planalto.gov.br/ccivil_03/ Leis/L8080.htm.

10. Sade C, Barros LMR, Melo JJM, et al. O uso da entrevista na pesquisa-intervenção participativa em saúde mental: o dispositivo GAM como entrevista coletiva. Ciênc. Saúde Colet. [internet]. 2013 [acesso em 2019 set 28]; 18(10):2813-2824. Disponível em: http:// dx.doi.org/10.1590/S1413-81232013001000006.

11. Galletti MC. Oficina em Saúde Mental: instrumento terapêutico ou intercessor clínico? Goiânia: UCG; 2004.

12. Bichuetti J, Fortuna C. O agente de saúde e a mudança: do espanto ao encanto. Interface [internet]. 2005 [acesso em 2017 abr 11]; 9(17). Disponível em: https://www.scielo.br/scielo.php?script=sci arttext\&pid=S1414-32832005000200024\&lng=pt\& tlng=pt.

13. Bardin L. Análise de Conteúdo. São Paulo: Edições 70; 2011.

14. Minayo MCS. O Desafio do Conhecimento: pesquisa qualitativa em saúde. São Paulo: Hucitec; 2006.

15. Cecílio LCO, Graça C. Rosimeire A. Os Mapas do Cuidado: o agir leigo na saúde. São Paulo: Hucitec; 2014.

16. Pereira Ld'Á, Silva KL, Andrade MFLB, et al. Educação Permanente em Saúde: uma prática possível. Rev. enferm. UFPE [publicação online]. 2018 [acesso em 2020 out 9]; 12(5):1469-79. Disponível 
em: https://periodicos.ufpe.br/revistas/revistaenfermagem/article/viewFile/231116/29010.

17. Comunicação Educa Saúde. EPS em Movimento: Laura Camargo Macruz Feuerwerker. 2014. [acesso em 2019 set 28]. Disponível em: http://www.youtube.com/watch?v=x791Rw9_B8k.

18. Mansano SRV. Transformações da subjetividade no exercício do trabalho imaterial. Estudos e Pesquisas em Psicologia [internet]. 2009 [acesso em 2019 set 25]; 9(2). Disponível em: http://www.revispsi.uerj. br/v9n2/artigos/pdf/v9n2al5.pdf.

19. Machado AGM, Wanderley LCS. Educação em Saúde. UNA-SUS | UNIFESP [internet]. [acesso em 2019 set 28]. Disponível em: https://www.unasus.unifesp.br/ biblioteca_virtual/esf/2/unidades_conteudos/unidade09/unidade09.pdf.

20. Noal MHO. Da internação à reabilitação: uma construção coletiva em Santa Cruz do Sul, RS. Cad. Bras. Saúde Mental [internet]. 2014 [acesso em 2019 set 29]; 6(14):27-41. Disponível em: http://incubadora.periodicos.ufsc.br/index.php/cbsm/article/view/1765.

21. Kastrup V. Aprendizagem, arte e invenção. Psicologia em Estudo [internet]. 2001 [acesso em 2019 set 28]; 6(1):17-27. Disponível em: http://www.scielo.br/ pdf/pe/v6nl/v6nla03.pdf.

22. Hardt M. O trabalho afetivo. In: Núcleo de Estudos da Subjetividade. Programa de Estudos Pós-Graduados em Psicologia Clínica da PUC-SP. O Reencantamento do Concreto. São Paulo: Hucitec; 2003.

23. Lima EMFA, Yasui S. Territórios e sentidos: espaço, cultura, subjetividade e cuidado na atenção psicossocial. Saúde debate [internet]. 2014 [acesso em 2019 set
29]; 38(102):593-606. Disponível em: http://www.scielo.br/pdf/sdeb/v38n102/0103-1104-sdeb-38-1020593. pdf.

24. Santos JPB, Lima RRT. Educação permanente em saúde para qualificar o acolhimento às mulheres vítimas de violência: debatendo uma proposta. Research, Society and Development. [internet]. 2020 [acesso em 2020 out 9]; 9(1). Disponível em: file://D:/Revista/ Downloads/Dialnet-EducacaoPermanenteEmSaudeParaQualificarOAcolhiment-7342178.pdf.

25. Brasil. Ministério da Saúde. Portaria n ${ }^{\circ} 3.088$, de 23 de dezembro de 2011. Institui a Rede de Atenção Psicossocial para pessoas com sofrimento ou transtorno mental e com necessidades decorrentes do uso de crack, álcool e outras drogas, no âmbito do Sistema Único de Saúde (SUS). Diário Oficial da União. 23 Dez 2011. [acesso em 2019 out 9]. Disponível em: http://bvsms.saude.gov.br/bvs/saudelegis/gm/2011/ prt3088_23_12_2011_rep.html.

26. Ceccim RB. Educação Permanente em Saúde: desafio ambicioso e necessário. Interface [internet]. 2005 [acesso em 2019 set 28]; 9(16):161-177. Disponível em: http://www.escoladesaude.pr.gov.br/arquivos/File/ textos\%20eps/educacaopermanente.pdf.

27. Paiva IL, Yamamoto OH. Em defesa da reforma psiquiátrica: por um amanhã que há de nascer sem pedir licença. Hist. Cienc. Saúde - Manguinhos [internet]. 2007 [acesso em 2019 out 7]; 14(2):549-569. Disponível em: http://dx.doi.org/10.1590/S010459702007000200009 .

Recebido em 20/11/2019

Aprovado em 14/07/2020

Conflito de interesses: inexistente

Suporte financeiro: não houve 